\title{
Thermally Stimulated Depolarized Current (TSDC) Analysis on the Structural Change of Regenerated Cellulose Membranes Caused by the Change in Water Content
}

\author{
Tomoko Hongo (née HiRasaki), Toshinori Koizumi, Chihiro Yamane, \\ and Kunihiko OKaJIMA \\ Fundamental Research Laboratory for Natural \& Synthetic Polymers, \\ Asahi Chemical Industries Co., Ltd., 11-7 Hacchonawate, \\ Takatsuki, Osaka 569, Japan
}

(Received May 21, 1996)

\begin{abstract}
Structural change of regenerated cellulose membranes caused by the vaporization of water was investigated with aid of thermally stimulated depolarized current (TSDC) analysis. For this purpose five kinds of regenerated cellulose membranes having different swelling anisotropy parameter $L_{\mathbf{t}}$ and plane orientation factor $f_{\|(1 \overline{1})}$ were utilized. The membranes first dipped in water at $25^{\circ} \mathrm{C}$ for $5 \mathrm{~min}$ were subject to TSC measurement as a function of annealing temperature $T_{\mathrm{a}}$ from 10 to $130^{\circ} \mathrm{C}$. The two broad TSC $\beta$ and TSC $\gamma$ relaxations were observed and the former peak was found to decrease in its depolarized current $I_{\beta}$ with an increase in $T_{\mathrm{a}}$ while $I_{\gamma}$ of the latter also decreases up to $T_{\mathrm{a}}=T_{\mathrm{t} 2}$ then increases. It was found that these relaxations were composed of at least three and two components, respectively, by thermal window analysis reducing to $\Delta S^{*}-\Delta H^{*}$ relation, and correspond to mechanical relaxations $\alpha_{\mathrm{H}_{2} \mathrm{O}}$ and $\beta$ observed on $\tan \delta-T$ curves. The peak temperatures $\left(T_{\beta}\right.$ and $\left.T_{\gamma}\right)$ and their currents $\left(I_{\beta}\right.$ and $\left.I_{\gamma}\right)$ as a function of $T_{\mathrm{a}}$, and $\ln T_{\beta}-1 / T_{\mathrm{a}}$ plot revealed two sudden molecular integration region around $T_{\mathrm{a}}=30-50$ and $T_{\mathrm{a}}=50-80^{\circ} \mathrm{C}$, of which former relates to the sudden change in long periodicity of (1T⿱10) $)$ plane. The ratio of $I_{\beta}$ and $I_{\gamma}$ at the above $T_{\mathrm{t} 2}$ was proved to be closely related to $L_{\mathrm{t}}$ and $f_{\|(1 \overline{1} 0)}$.

KEY WORDS Regenerated Cellulose / Thermally Stimulated Depolarized Current / Swelling Anisotropy /Amorphous Structure / Vaporization of Water /
\end{abstract}

Dimensional stability of the regenerated cellulose shaped articles has been one of ultimate objects in comparison with natural cotton which exhibits higher tenacity and modulus in wet state than in dry state. In an attempt to seek for the answer authors ${ }^{1}$ studied previously the controlling factors for the swelling anisotropic behavior of the regenerated cellulose membranes prepared from cellulose/aqueous cuprammonium hydroxide solution and cellulose/dimethylacetamide-lithium chloride solution, and found that the morphological and super-molecular structural parameters are closely related to the swelling anisotropy parameter $L_{t}$ (the degree of swelling to the thickness direction of the membrane), which is in turn controlled by coagulation systems applied for the preparation of regenerated cellulose membranes. The most decisive parameter controlling $L_{\mathrm{t}}$ was proved to be the orientation parameter $f_{\|(1 \overline{1} 0)}$ for (110) crystal plane (that is, the degree of hydrogen bonding to the membrane thickness direction), which is related to amorphous parameters concerning for $\alpha_{\mathrm{H}_{2} \mathrm{O}}, \beta$, and $\gamma$ relaxations. ${ }^{1}$ Authors ${ }^{1}$ also demonstrated a critical structural change with long periodicity in (110) crystal plane of regenerated cellulose membranes by absorption of a definite amount of water. All these phenomenological findings are however still insufficient to elucidate the reason why such structural change or swelling behavior takes place. It is quite natural to think that such swelling behavior or structural change should start from so-called amorphous part and then more detailed analysis on amorphous structure is required. For this purpose, thermally stimulated current (TSC) analysis, which is more sensitive tool to detect the relaxation phenomena for the material composing of molecular chains with dipolar nature such as cellulose, is suitable. Therefore, in this paper as an extension of the previous study, we investigate the structural change in amorphous region induced by water for the regenerated cellulose membranes by means of TSC analysis and will discuss the results in view of swelling behavior of the cellulose.

\section{EXPERIMENTAL}

\section{Regenerated Cellulose Membranes}

Five cellulose membranes $\left(\mathrm{C}_{10} \mathrm{Na}_{11}, \mathrm{C}_{10} \mathrm{Hs}_{15}, \mathrm{C}_{07^{-}}\right.$ $\mathrm{Ca}_{10}, \mathrm{C}_{07} \mathrm{Ac}_{30}, \mathrm{D}_{03} \mathrm{~T}_{50}$ ) with different swelling anisotropy employed previously ${ }^{1}$ were used in this study and some morphological and structural parameters and swelling parameters are cited from the literature ${ }^{1}$ and are listed in Table I. The sample membranes were first dipped in water freely at $25^{\circ} \mathrm{C}$ for $5 \mathrm{~min}$ and the excess water on the surface was wiped out with a filter paper. Here, the parameters are the same as those used in the previous paper ${ }^{1}: L_{t}$, degree of swelling in the thickness direction of membrane; $P_{\mathrm{r}}$, porosity; $\chi_{\mathrm{c}}$, crystallinity determined by X-ray diffraction method; $f_{\|(1 \overline{1} 0)}$, parallel orientation factor of (1 $1 \overline{1} 0)$ plane crystal to the membrane surface; $T_{\max \beta}$, maximum temperature for $\beta$ relaxation; $\tan \delta_{\max \beta}$, maximum loss tangent for $\beta$ relaxation.

\section{Thermally Stimulated Current (TSC) Analysis}

TSC measurements were carried out using TSC/RMA spectrometer 91000 (Rigaku/Solomat) for five dried membrane samples prepared by acetone-substitution method and the swollen membranes which were then annealed at desired temperatures $\left(T_{\mathrm{a}}=0-120^{\circ} \mathrm{C}\right)$ before measurement, aligned between electrodes in a sample chamber, filled with $\mathrm{He}$ gas. Global measurements for all samples as a function of $T_{\mathrm{a}}$ and thermal window 
Table I. Some morphological, structural and swelling parameters of the regenerated cellulose membranes and their preparation conditions

\begin{tabular}{|c|c|c|c|c|c|c|c|c|c|c|}
\hline \multirow{2}{*}{ Sample $^{\mathrm{a}}$} & \multirow{2}{*}{ Coagluant } & \multirow{2}{*}{$\frac{\text { Porosity }}{P_{\mathrm{r}} / \%}$} & \multirow{2}{*}{$\frac{\text { Thickness }}{I_{\mathrm{d}} / \mu \mathrm{m}}$} & \multirow{2}{*}{$\frac{\text { Crystallinity }}{\chi_{\mathrm{c}} / \%}$} & \multirow{2}{*}{$f_{\|(1 \overline{1} 0)}$} & \multicolumn{2}{|c|}{ Mechanical relaxations } & \multicolumn{3}{|c|}{ Swelling parameters } \\
\hline & & & & & & $T_{\max \beta} / \mathrm{K}$ & $\tan \delta_{\max \beta}$ & $L_{\mathrm{t}}$ & $L_{1}$ & $V_{\mathrm{s}}$ \\
\hline $\mathrm{C}_{10} \mathrm{Na}_{11}$ & $\mathrm{NaOH}$ & 7.6 & 15.4 & 34.2 & 0.350 & 191 & 0.049 & 1.97 & 1.07 & 2.26 \\
\hline $\mathrm{C}_{10} \mathrm{Hs}_{15}$ & $\mathrm{H}_{2} \mathrm{SO}_{4}$ & 22.0 & 32.9 & 4.20 & 0.520 & 198 & 0.044 & 1.99 & 1.08 & 2.32 \\
\hline $\mathrm{C}_{07} \mathrm{Ca}_{10}$ & $\mathrm{CaCl}_{2}$ & 16.0 & 15.9 & 21.2 & 0.175 & 204 & 0.046 & 1.71 & 1.08 & 1.99 \\
\hline $\mathrm{C}_{07} \mathrm{Ac}_{30}$ & Acetone & 66.0 & 52.0 & 13.3 & 0.096 & 215 & 0.038 & 1.61 & 1.12 & 2.02 \\
\hline
\end{tabular}

${ }^{a}$ First term $\mathrm{C}$ and $\mathrm{D}$ denote cuprammonium solution and $\mathrm{DMAc} / \mathrm{LiCl}$ solution, the first number means cellulose concentration, last number means coagulant concentration.

measurements for one sample $\left(\mathrm{C}_{08} \mathrm{Hs}_{15}\right)$ with two states, one having an equilibrium water content ( $c a .10 \mathrm{wt} \%)$ and the other having less water $(c a .5 \mathrm{w} \mathrm{t} \%)$, were carried out as follows:

Global measurements: Samples were polarized at a given polarizing temperature $T_{\mathrm{p}}\left(=75^{\circ} \mathrm{C}\right)$ by imposing a polarizing voltage $V_{\mathrm{p}}\left(=1800 \mathrm{~V} \mathrm{~mm}^{-1}\right)$ for a given polarizing time $t_{\mathrm{p}}(=2 \mathrm{~min})$ and the samples were freezed under $V_{\mathrm{p}}$ to $-150^{\circ} \mathrm{C}$ so as to quench the polarized state of the polymer molecules. Subsequently, the depolarization of samples was carried out at a depolarizing temperature $T_{\mathrm{d}}\left(=-150^{\circ} \mathrm{C}\right)$ for a depolarizing time $t_{\mathrm{d}}$ $(=2 \mathrm{~min})$ and the samples were heated at a rate of $7^{\circ} \mathrm{Cmin}^{-1}$. TSC curve (depolarized current $J$-temperature $T$ curve) was obtained by recording $J$ generated on the heating process.

Thermal window measurements: This is a technique to polarize a molecular state having a particular relaxation time within a polarizing mechanism which has some distribution in relaxation time. In the present experiment, the polarizing temperature range $\left(\Delta T=T_{\mathrm{p}}-\right.$ $\left.T_{\mathrm{d}}\right)$ was set to $5^{\circ} \mathrm{C}$. Under a $V_{\mathrm{p}}\left(=1800 \mathrm{~V} \mathrm{~mm}^{-1}\right)$ the polarization at a $T_{\mathrm{p}}$ was made for $2 \mathrm{~min}$ and the sample was depolarized at $T_{\mathrm{d}}=T_{\mathrm{p}}-5^{\circ} \mathrm{C}$ for $t_{\mathrm{d}}=2 \mathrm{~min}$. At this instant, the most of dipolar molecules having relaxation time less than 2 min deem to be depolarized. Then, the sample was further cooled down to $T_{\mathrm{p}}-50^{\circ} \mathrm{C}$ so that remainning polarized moiety was freezed, and the TSC curve was obtained by heating to $T_{\mathrm{p}}+50^{\circ} \mathrm{C}$ with the heating rate of $7^{\circ} \mathrm{C} \mathrm{min}^{-1}$. This series of procedures were performed at every $5^{\circ} \mathrm{C}$ between $T_{\mathrm{p}}=-150 \sim-30^{\circ} \mathrm{C}$ in order to obtain the relaxation map with an unique relaxation mechanism.

The data thus obtained were analyzed basically by plotting the activation enthalpy $\Delta H^{*} v s$. the activating entropy $\Delta S^{*}$ according to the following equation ${ }^{2}$ :

$$
\ln \tau-\ln h / k T=\Delta H^{*} / R T-\Delta S^{*} / R
$$

Here, $\tau, h, k, R$, and $T$ are the relaxation time, Planck constant, Boltzman constant, gas constant, and peak temperature, respectively. If some of the data points falls on a straight line, these relaxations are regarded to have a similar relaxation mechanism.

\section{RESULTS AND DISCUSSION}

Figure 1 shows the plots of depolarized current $I_{\mathrm{x}} v s$. temperature $T$ for typical membranes. The measurements were carried out at various annealing temperatures $T_{\mathrm{a}}$. 1078
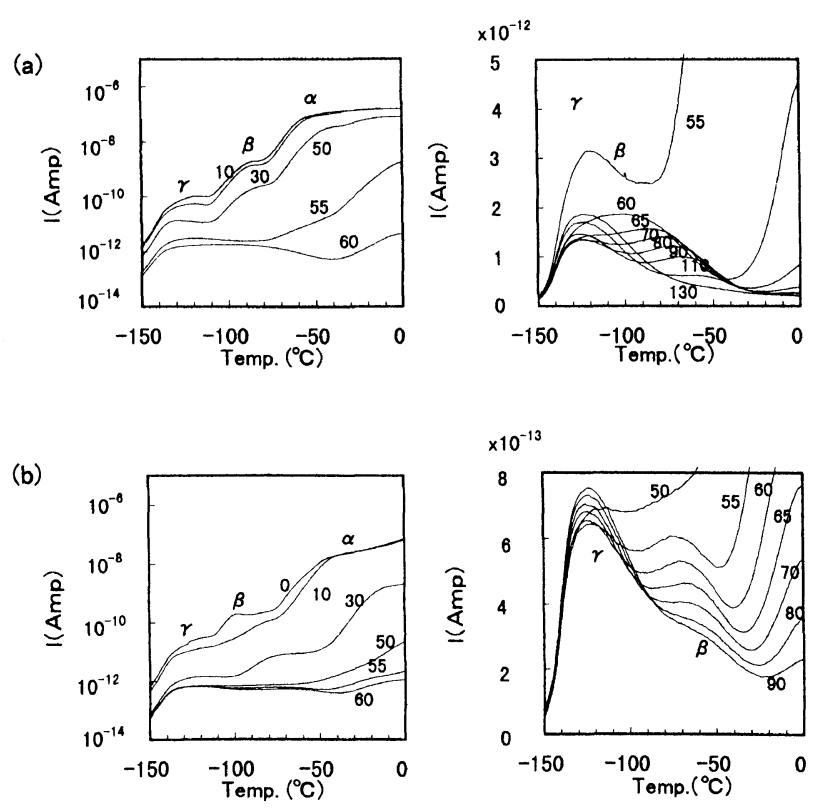

Figure 1. Thermally stimulated current (TSC) spectra of various cellulose membranes as a function of annealing temperature $T_{\mathrm{a}}$. a, $\mathrm{C}_{07} \mathrm{Ca}_{10} ; \mathrm{b}, \mathrm{D}_{03} \mathrm{~T}_{50}$. The number shows the annealing temperature $T_{\mathrm{a}}$.

Owing to the huge current difference as a function $T_{\mathrm{a}}$, $\log I_{\mathrm{x}}$ was used for lower $T_{\mathrm{a}}$ as ordinate axis. As was reported in the previous paper, ${ }^{1}$ since the most typical mechanical relaxation difference for membranes with different swelling anisotropy was seen at lower temperature region, the special attention was also placed below $0^{\circ} \mathrm{C}$ in the present case. Note that the rise in $T_{\mathrm{a}}$ corresponds to the diminishing of the water content in membranes, although it could not be determined quantitatively. In this regard, the water content in the membranes might be around $10 \mathrm{wt} \%$ at $T_{\mathrm{a}}=c a$. 55$60^{\circ} \mathrm{C}$ by comparison of the TSC curves for the membranes with that for the membrane having an equilibrium water content ( $c a .10 \mathrm{wt} \%)$. Then the water content might decrease with increase in $T_{\mathrm{a}}$ over $60^{\circ} \mathrm{C}$. For example, the water content at $T_{\mathrm{a}}=90^{\circ} \mathrm{C}$ for membranes is ca. 5-6 $\mathrm{wt} \%$. All the membrane proved to give quite similar TSC patterns as a function of $T_{\mathrm{a}}$. At $T_{\mathrm{a}}=0$ (that is, at completely wet state) three peaks are observed at $c a$. $-125,-80$, and $-55^{\circ} \mathrm{C}$. These peaks might correspond to the three TSC peaks ( $\mathrm{ca} .-126,-70$, and $50^{\circ} \mathrm{C}$ ) observed for cellophane reported by Sawatari. ${ }^{3}$ These peaks are referred to as $\alpha, \beta$, and $\gamma$ relaxations from higher temperature side. By considering the facts that $I_{\mathrm{x}}$ for TSC $\gamma$ and TSC $\beta$ at $T_{\mathrm{a}}<55^{\circ} \mathrm{C}$ is almost one order 

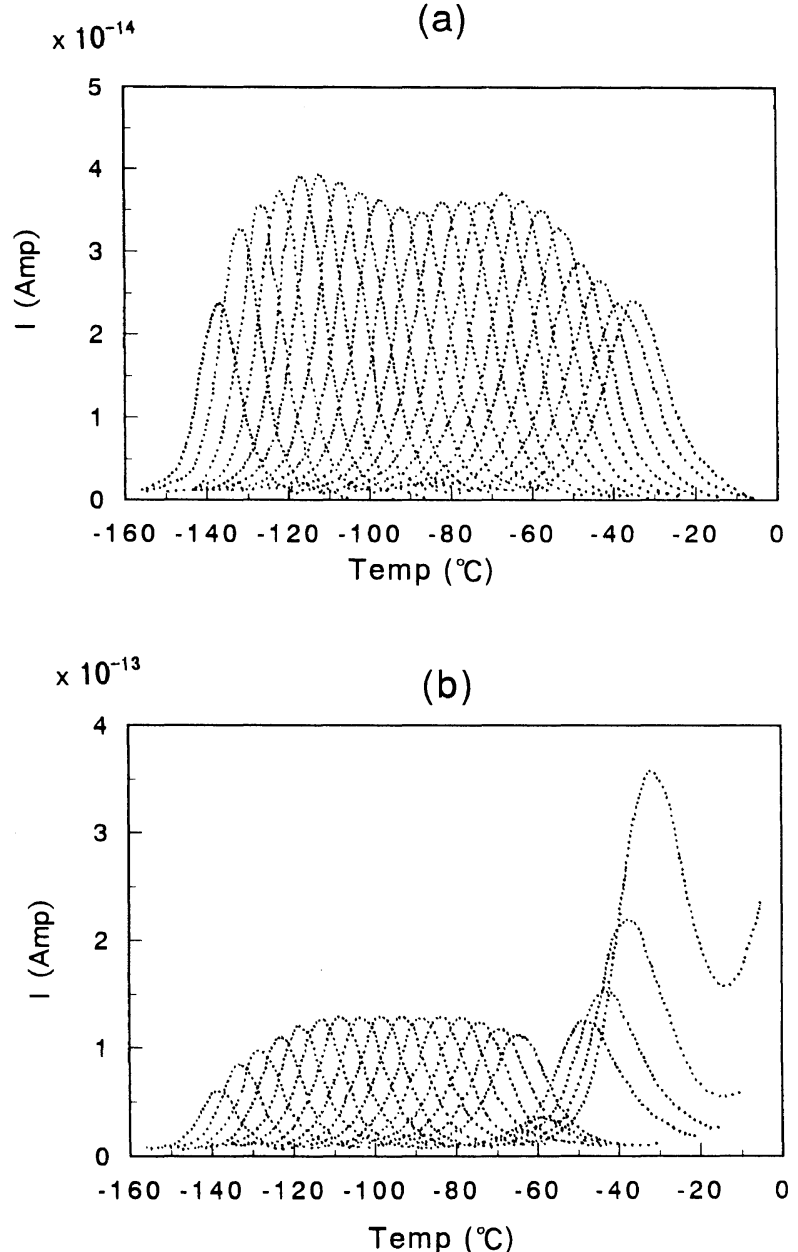

Figure 2. Thermal window spectra of cellulose membrane $\mathrm{C}_{10} \mathrm{Hs}_{15}$ with two different water contents. a, less than equilibrium water content; b, equilibrium water content.

larger than that obtained at $T_{\mathrm{a}}>55^{\circ} \mathrm{C}$ and the water content in the membranes at $T_{\mathrm{a}}<55^{\circ} \mathrm{C}$ is larger than the equilibrium, these two TSC peaks might contain the information on water itself associated with cellulose molecular chains. Koizumi and Okajima et al. have found five TSC peaks at $c a$. $-140,-125,-105,-78$, and $-50^{\circ} \mathrm{C}$ for ice ${ }^{4}$ and then we can not deny the possibility that some of these peaks are reflected on the TSC peak observed at $c a$. $-125,-80$, and $-55^{\circ} \mathrm{C}$ either as a result of existence of free water in the system or as a result of interaction with cellulose in the present study, as insisted from TSC analysis on water/cellulose system by Pissis. ${ }^{5}$ With an increase in $T_{\mathrm{a}}$, apparent peak position of $\gamma$ relaxation $\left(T_{\max \gamma}\right)$ does not seem to change at a glance while other two $\left(T_{\max \beta}, T_{\max \alpha}\right)$ for $\beta$ and $\alpha$ relaxations seem to shift clearly towards higher temperature side. At higher $T_{\mathrm{a}}$ there are two main broad peaks visible below $0^{\circ} \mathrm{C}$. However, the pattern of $\gamma$ relaxation peak at higher $T_{\mathrm{a}}$ is not symmetry about the peak temperature axis and it is reasonable to have another peaks at higher temperature side (around $-110 \sim-100^{\circ} \mathrm{C}$ ). Therefore, an apparent one $\gamma$ relaxation may have at least two mechanisms. Similar discussion can be applied to $\beta$ peak.

In order to examine the above point, thermal window spectra in the temperature region of $-150 \sim-30^{\circ} \mathrm{C}$ for the membrane $\mathrm{C}_{10} \mathrm{Hs}_{15}$ with two states (a, less than equilibrium water content ( $c a .5 \mathrm{wt} \%)$; b, an equilibrium

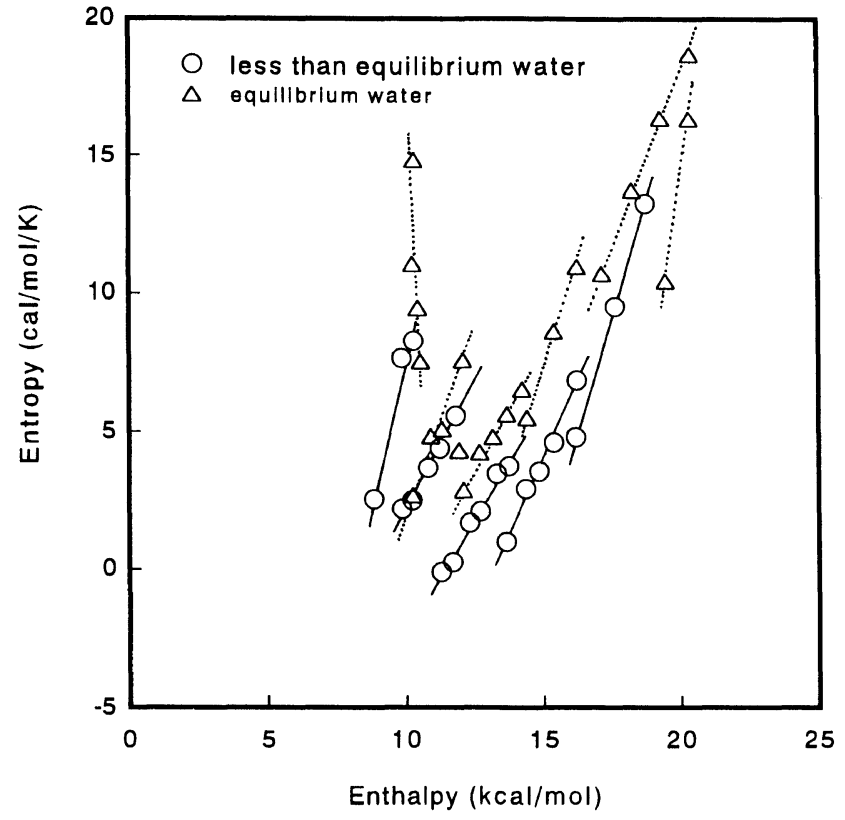

Figure 3. The activation entropy $\Delta S^{*}$-activation enthalpy $\Delta H^{*}$ relation deducted from Figure 2. $\bigcirc$, less than equilibrium water content; $\triangle$, equilibrium water content.

water content $(c a .10 \mathrm{wt} \%))$ are shown in Figure 2. The figure shows that owing to the relatively large water content in the membrane the latter membrane probably give $\alpha$ relaxation peak beside $\gamma$ and $\beta$ at somewhat higher temperature side about $-30^{\circ} \mathrm{C}$. Although the depolarized temperature interval is somewhat rough, $\Delta H^{*}$ $\Delta S^{*}$ relation belonging to each unique relaxation mechanism is plotted in Figure 3. In the case where water content in cellulose is less than equilibrium, 5 relaxations with positive $\Delta H^{*}-\Delta S^{*}$ relation are observed. Two mechanisms in the lower temperature side might belong to TSC $\gamma$ relaxation and other 3 mechanisms to TSC $\beta$ judged from peak temperature region in the global $I_{\mathrm{x}}-T$ curve. Contrarily to this, in the case of equilibrium water content in cellulose, 5 relaxations with positive $\Delta H^{*}-\Delta S^{*}$ relation are observed and one of them is located outside the higher temperature limitation of TSC $\beta$ region, and in addition one relaxation with negative $\Delta H^{*}-\Delta S^{*}$ relation is seen in the lowest temperature region examined here. In similar manner, one negative and one positive mechanism in the lower temperature region is attributable to TSC $\gamma$ and subsequent positive 3 mechanisms are assigned to TSC $\beta$. Thus, $\gamma$ and $\beta$ relaxation peaks detected by TSC compose of at least two and three components, respectively. As is described before, one mechanism (lower temperature side) for $\gamma$ relaxation exhibits the completely reversed $\Delta S^{*}-\Delta H^{*}$ relation depending on water content of the membrane. The reason for the appearance of negative $\Delta S^{*}-\Delta H^{*}$ relation is not clear at present but it could be explained by that the mechanism giving negative $\Delta S^{*}-\Delta H^{*}$ relation is closely related to the structural formation by water mobility, hence, is quite sensitive water. The other positive $\gamma$ component is relatively non-sensitive to water since the absolute $\Delta S^{*}$ and $\Delta H^{*}$ values and its slope are almost similar for both systems with different water content. This conclusion is also supported by the facts that $\Delta S^{*}$ values of mechanisms belonging to TSC $\beta$ is always larger 


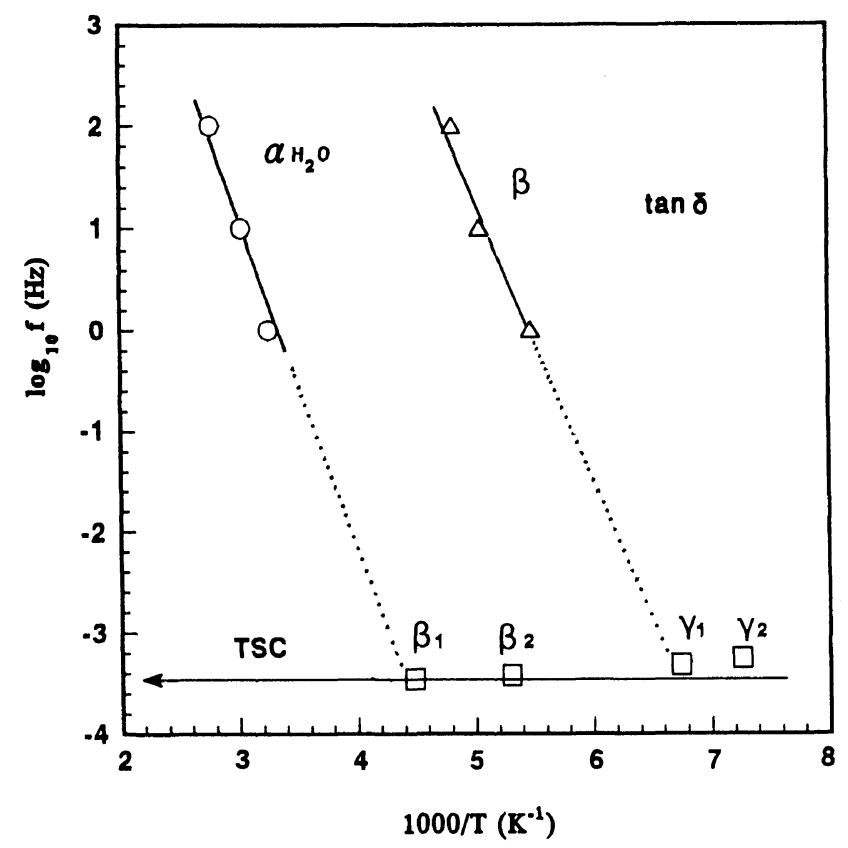

Figure 4. Correlation between peak temperatures detected by $\tan \delta$ and TSC measurement, judged from their frequency dependence.

for the system with equilibrium water content than for the less water system at constant $\Delta H^{*}$ level, indicating that this TSC $\gamma$ relaxation component is relatively nonsensitive to water. This explanation might be quite comparative for $\beta_{1}$ and $\beta_{2}$ peaks on $\tan \delta-T$ curve, of which $\beta_{2}$ appears with greatly depressed intensity by organic solvent coagulation in the process of membrane preparation, ${ }^{1}$ and in turn the $\beta_{1}$ peak appears as a main peak in this temperature region by these treatments. In our previous work ${ }^{1}$ on the mechanical relaxation of the same membranes we have reported several peaks attributable to $\alpha_{\mathrm{H}_{2} \text { O }}$ relaxation in the wide range of temperature region around room temperature, two peaks attributable to $\beta$ ( $\beta_{1}$ and $\beta_{2}$ from higher temperature side) relaxation in $-90 \sim-60^{\circ} \mathrm{C}$ and one peak for $\gamma$ relaxation around $-125^{\circ} \mathrm{C}$. Thus, TSC $\beta$ might correspond to $\alpha_{\mathrm{H}_{2} \mathrm{O}}$ mechanical relaxation by $\tan \delta-T$ analysis. Because of the highest slope of $\Delta S^{*}-\Delta H^{*}$ relation, one another positive mechanism seen in the equilibrium water system might be due to TSC $\alpha$ and probably corresponds to $\alpha_{\text {sh }}$ at $115-200^{\circ} \mathrm{C}$ or $\alpha_{2}$ at $140-290^{\circ} \mathrm{C}$ in $\tan \delta-T$ analysis. These absorptions have already assigned to micro-Brownian motion of segments in amorphous regions separated depending on packing density of polymer segment with moderately developed intermolecular hydrogen bond. ${ }^{6,7}$ The above conclusion can be verified by Figure 4, where the frequency $(f)$ dependence of each $\tan \delta$ peak temperature $T_{\mathrm{p}}$, that is ( $f$ vs. $1 / T_{\mathrm{p}}$ plot) is shown and $f$ is extrapolated to frequency region ( $c a .3 \times 10^{-4} \mathrm{~Hz}$ ) employed for TSC measurement. In addition, given peaks and frequency used for $\tan \delta$ measurement $(10 \mathrm{~Hz})$ eq 1 reveals that peak temperatures $-120,-74.5$, and $-50^{\circ} \mathrm{C}$ by TSC correspond to $-76,-17$, and $11^{\circ} \mathrm{C}$, respectively. Then, we can finally conclude that $\gamma$ relaxation (at least two peaks) by TSC corresponds to mechanical relaxation $\beta$ (two peaks) by $\tan \delta-T$ curves and $\beta$ by TSC corresponds to $\alpha_{\mathrm{H}_{2} \mathrm{O}}$ by $\tan \delta$, as illustrated in Figure 4 . Although, 1080 (a)

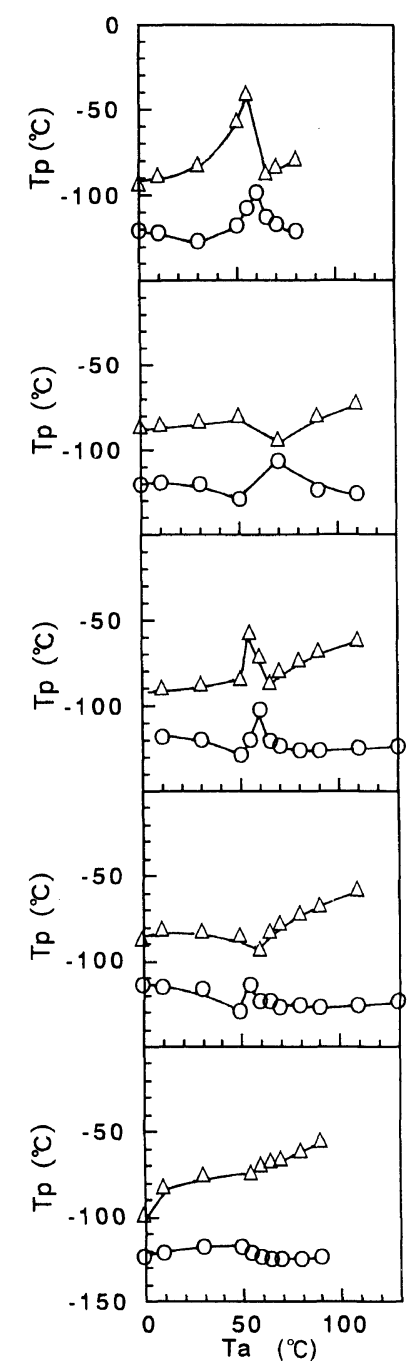

Figure 5. Dependence of peak temperatures $T_{\mathrm{p}}\left(T_{\beta}\right.$ and $\left.T_{\gamma}\right)$ on annealing temperature $T_{\mathrm{a}}$ for various cellulose membranes. $\bigcirc, T_{\gamma} ; \triangle$, $T_{\beta}$. a, $\mathrm{C}_{10} \mathrm{Na}_{11} ; \mathrm{b}, \mathrm{C}_{10} \mathrm{Hs}_{15} ; \mathrm{c}, \mathrm{C}_{07} \mathrm{Ca}_{10} ; \mathrm{d}, \mathrm{C}_{07} \mathrm{Ac}_{30} ; \mathrm{e}, \mathrm{D}_{03} \mathrm{~T}_{50}$.

Pissis ${ }^{5}$ insisted that TSC $\gamma$ is attributable to motion of water strongly interacting with cellulose, this is not always acceptable by the reason discussed above. Further, Manabe et al. ${ }^{8}$ reported very recently a $\tan \delta$ peak derived from fusion of water existing in the pore surrounded by cellulose particles in temperature region of -30 to $10^{\circ} \mathrm{C}$ and this possibility might not be denied for the relaxation appeared at just higher than $-30^{\circ} \mathrm{C}$ detected in an equilibrium water system to which we have assign mechanical relaxation $\alpha_{\mathrm{sh}}$ or $\alpha_{2}$ here.

Apparent $T_{\max \gamma}$ and $T_{\max \beta}$ for each membrane detected from Figure 1 are plotted against $T_{\mathrm{a}}$ in Figure 5 . Note that apparent $T_{\max \gamma}$ and $T_{\max \beta}$ are an average value for 2 and 3 relaxations included, respectively. A close inspection however revealed that from view point of change in $T_{\max \gamma}$ the membranes can be classified into two groups, one is the membrane prepared from aqueous coagulation systems (Group A) and the other is the membrane prepared by organic solvent coagulation systems (Group B). For Group A $T_{\max \gamma}$ shifts abruptly towards higher temperature around $T_{\mathrm{a}}=c a .60-70^{\circ} \mathrm{C}$ (hereafter this $T_{\mathrm{a}}$ is termed as $T_{\mathrm{t}}$ ), then returning to lower temperature. Such drastic change is not observed for Group B although a clear transition is observed at $T_{\mathrm{t}}=c a$. 
(a)

(b)

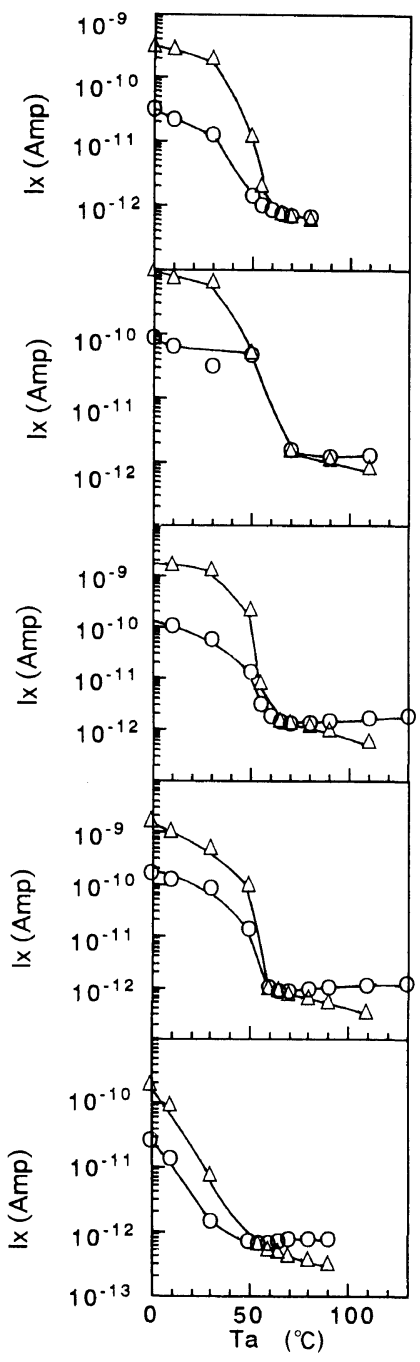

Figure 6. Dependence of peak current $I_{\mathrm{x}}\left(I_{\beta}\right.$ and $\left.I_{\gamma}\right)$ on annealing temperature $T_{\mathrm{a}}$ for various cellulose membranes. $O, I_{\gamma} ; \Delta, I_{\beta}$. a, $\mathrm{C}_{10} \mathrm{Na}_{11} ; \mathrm{b}, \mathrm{C}_{10} \mathrm{Hs}_{15} ; \mathrm{c}, \mathrm{C}_{07} \mathrm{Ca}_{10} ; \mathrm{d}, \mathrm{C}_{07} \mathrm{Ac}_{30} ; \mathrm{e}, \mathrm{D}_{03} \mathrm{~T}_{50}$.

$60^{\circ} \mathrm{C}$. Similar tendency is also observed for $T_{\max \beta}$. Note that the former group is also characterized by relatively larger swelling anisotropy $\left(L_{\mathrm{t}} \geqq 1.71\right)$ and the latter group by smaller $\left(L_{\mathrm{t}} \leqq 1.61\right)$. Such transition is also clearly pictured in the intensity- $T_{\mathrm{a}}$ plot, as shown in Figure 6. Intensity of $\beta$ relaxation $\left(I_{\beta}\right)$ and the intensity of $\gamma$ relaxation $\left(I_{\gamma}\right)$ exhibit similar tendency as a function of $T_{\mathrm{a}} \cdot T_{\mathrm{t}}$ judging from Figure 6 is almost $50^{\circ} \mathrm{C}$ for most membranes, except for $\mathrm{D}_{03} \mathrm{~T}_{50}\left(T_{\mathrm{t}}=30-50^{\circ} \mathrm{C}\right)$, which is only one example prepared from cellulose solution dissolved in organic solvent. Such transition at $T_{\mathrm{a}}=c a$. $50-60^{\circ} \mathrm{C}$ probably relate to an abrupt change in the long-periodicity detected by X-ray diffraction analysis on cellulose membrane when water content in membrane is $30-40 \mathrm{wt} \%$, reported by Yamane et al. ${ }^{9}$ Note that the structural transition in the present case was found at the lower water content region than that found for small-angle X-ray diffraction experiment. This might be due to the experimental difference: In the present case, the structural change was performed by annealing repeatedly and measurement temperature was lower than that for X-ray experiment. The sample $\mathrm{D}_{03} \mathrm{~T}_{50}$ prepared from organic solvent system have low crystallinity and $f_{\|(1 \overline{1} 0)}$ due to the relatively low hydrogen-bondinginduced structural changes, compared with other mem- (a)

(b)

(c)

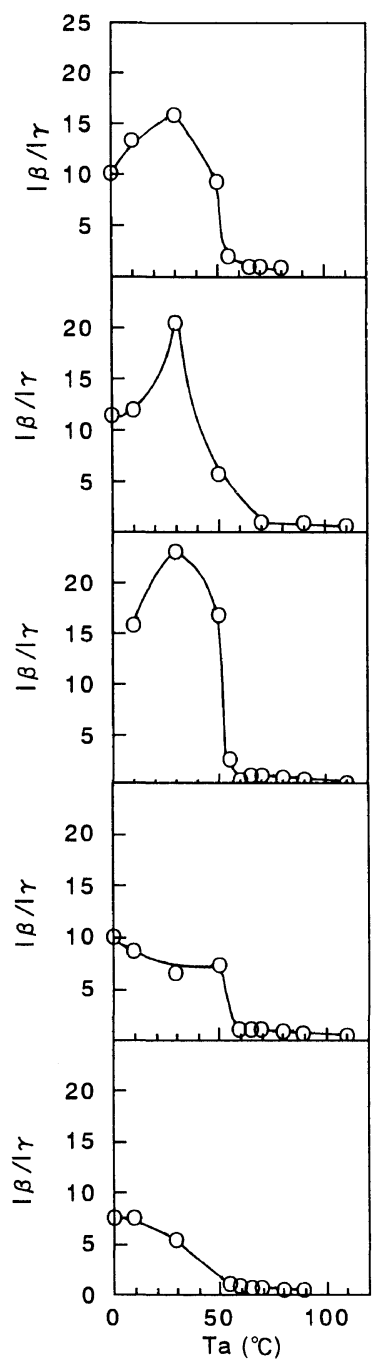

Figure 7. Plot of $I_{\beta} / I_{\gamma}$ vs. annealing temperature $T_{\mathrm{a}} . \mathrm{a}, \mathrm{C}_{10} \mathrm{Na}_{11} ; \mathrm{b}$, $\mathrm{C}_{10} \mathrm{Hs}_{15} ; \mathrm{c}, \mathrm{C}_{07} \mathrm{Ca}_{10} ; \mathrm{d}, \mathrm{C}_{07} \mathrm{Ac}_{30} ; \mathrm{e}, \mathrm{D}_{03} \mathrm{~T}_{50}$.

branes prepared by aqueous solvent systems. This situation corresponds to the small portions of molecular aggregates which act as base-matrix for higher integration of them by water, as proposed previously. ${ }^{1}$

Peak intensity ratio $I_{\beta} / I_{\gamma}$ is plotted against $T_{\mathrm{a}}$ in Figure 7. This plot more clearly detects $T_{\mathrm{t}}$. Obviously, the membranes in Group A show a maximum at $T_{\mathrm{a}}=30^{\circ} \mathrm{C}$ and the ratio decreases abruptly up to $T_{\mathrm{a}}=50-60^{\circ} \mathrm{C}$ but for Group B such maximum is not observed, only showing the latter abrupt change at $T_{\mathrm{a}}=c a .50-60^{\circ} \mathrm{C}$. Here, the former and latter $T_{\mathrm{a}}$ are referred to as $T_{\mathrm{t} 1}$ and $T_{\mathrm{t} 2}$, respectively and are listed in Table II. TSC $\beta$ and TSC $\gamma$ correspond to mechanical relaxations $\alpha_{\mathrm{H}_{2} \mathrm{O}}$ and $\beta$, respectively. Then a maximum $I_{\beta} / I_{\gamma}$ at $T_{\mathrm{a}}=30^{\circ} \mathrm{C}$ means that the initial stage of vaporization of water from the membranes facilitates strongly the reorientation of dipolar group ( $\mathrm{OH}$ group) in the molecular motion associated with water to the direction of membrane thickness under TSC measuring conditions, compared with that of local segmental motion, before the abrupt structural transition at $T_{\mathrm{a}}=c a .50-60^{\circ} \mathrm{C}$. This then indicates that such structural transition (change in the long-periodicity structure) takes place as a result of the molecular integration of the moving mass characterized by TSC $\beta$ or mechanical $\alpha_{\mathrm{H}_{2} \mathrm{O}}$ for Group A membranes. With the above consideration the intensity of $\gamma$ re- 
Table II. Super-molecular parameters of regenerated cellulose membranes ${ }^{\mathrm{a}}$

\begin{tabular}{|c|c|c|c|c|c|c|c|c|c|c|c|c|}
\hline \multirow{3}{*}{ Sample } & \multirow{3}{*}{$\frac{\text { X-Ray }}{f_{\|(1 \overline{1} 0)}}$} & \multicolumn{10}{|c|}{ TSC relaxations } & \multirow{3}{*}{$\begin{array}{c}\begin{array}{c}\text { Swelling } \\
\text { ratio }\end{array} \\
L_{\mathrm{t}}\end{array}$} \\
\hline & & $I_{\gamma 0}$ & $I_{\gamma \mathrm{m}}$ & $I_{\beta \mathrm{m}}$ & $I_{\beta \mathrm{m}} / I_{\gamma \mathrm{m}}$ & $T_{\mathrm{t} 1}$ & $T_{12}$ & $\Delta \mathrm{E}_{1-1}$ & $\Delta_{1-2}$ & $\Delta \mathrm{E}_{2-1}$ & $\Delta \mathrm{E}_{2-2}$ & \\
\hline & & \multicolumn{4}{|c|}{$10^{12} \mathrm{~A}$} & \multicolumn{6}{|c|}{${ }^{\circ} \mathrm{C}$} & \\
\hline $\mathrm{C}_{10} \mathrm{Na}_{11}$ & 0.350 & $>0.70$ & $(0.68)^{*}$ & $(0.63)^{*}$ & $(0.92)^{*}$ & 30 & 65 & 71.5 & 267.3 & 137.8 & ND & 1.97 \\
\hline $\mathrm{C}_{10} \mathrm{Hs}_{15}$ & 0.520 & $>1.20$ & 1.27 & 1.19 & 0.94 & 30 & 70 & 18.2 & 144.8 & ND & 144.9 & 1.99 \\
\hline $\mathrm{C}_{07} \mathrm{Ca}_{10}$ & 0.175 & $>1.18$ & 1.47 & 1.00 & 0.68 & 30 & 60 & 30.2 & 1237.2 & 222.8 & 112.5 & 1.71 \\
\hline $\mathrm{C}_{07} \mathrm{Ac}_{30}$ & 0.096 & 1.15 & 0.93 & 0.52 & 0.56 & ND & 60 & 28.7 & ND & 399.9 & 135.2 & 1.61 \\
\hline $\mathrm{D}_{03} \mathrm{~T}_{50}$ & 0.094 & $>0.30$ & 0.75 & 0.30 & 0.40 & ND & 55 & 75.0 & ND & 174.0 & 143.9 & 1.58 \\
\hline
\end{tabular}

${ }^{\text {a }} \mathrm{ND}$, not detected. $I_{\gamma \mathrm{m}}, I_{\beta \mathrm{m}}$ value at $T_{\mathrm{a}}=90^{\circ} \mathrm{C} ;()^{*}, T_{\mathrm{a}}=80^{\circ} \mathrm{C}$.

laxation $\left(I_{\gamma 0}\right)$ at higher $T_{\mathrm{a}}$ where $\beta$ relaxation apparently disappears is a measure for some inherent molecular motion of amorphous region not influenced by the action of water and associated with crystalline state since $\gamma$ peak is reported to be greatly depressed or to disappear with an increase in crystallinity of cellulose. ${ }^{10}$ The present observation of sudden change in TSC pattern as a function of $T_{\mathrm{a}}$ should be related to the sudden integration of molecular chains into the higher order molecular packing state with decreasing of water in the polymer but requiring the existence of water to some extent, as was described before. In other words, the intensity of $\gamma$ relaxation $\left(I_{\gamma \mathrm{m}}\right)$ at the corresponding $T_{\mathrm{t} 2}$ is a measure for the water-induced segmental motion requiring the above sudden change. In addition, $\beta$ relaxation is quite sensitive to water, then the intensity of $\beta$ relaxation $\left(I_{\beta \mathrm{m}}\right)$ at the above $T_{\mathrm{t} 2}$ is an index of amorphous content which is composed of very mobile segments against water. Thus, a parameter defined as $I_{\beta \mathrm{m}} / I_{\gamma \mathrm{m}}$ is a critical value indicating the easiness of the molecular integration into higher order of molecular packing as mentioned above. The parameters $I_{\gamma 0}$ and $I_{\beta \mathrm{m}} / I_{\gamma \mathrm{m}}$ are listed also in Table II. Unfortunately, $I_{\gamma_{0}}$ is not estimated correctly but those of membranes in Group A tends to be larger than those for group B, suggesting that structural change during evaporation of water from the samples is larger for Group A than that for Group B. This argument is also confirmed by $I_{\beta \mathrm{m}} / I_{\gamma \mathrm{m}}$, and is closely correlated with swelling anisotropy parameter $L_{\mathrm{t}}$ and the plane orientation factor $f_{\|(1 \overline{1} 0)}$, as shown in Figure 8.

As an tentative trial the plot of reciprocal of annealing temperature $\left(1 / T_{\mathrm{a}}\right)$ and logarithm of $\beta$ relaxation peak temperature $\left(\ln T_{\max \beta}\right)$ is shown in Figure 9 and the slopes are indices for a kind of apparent activation energy parameter to cause segmental motion related to the vaporization of the existing water in membranes. It is obvious that all membranes has two non-consecutive $T_{\mathrm{a}}$ regions before (Region 1) and beyond (Region 2) $T_{\mathrm{a}}=c a$. $50^{\circ} \mathrm{C}$. The suffix of $\mathrm{E}$ shows the Region 1 or 2 . For Group A two linear relations at lower $T_{\mathrm{a}}$ region and one or two linear relations at higher $T_{\mathrm{a}}$ region are seen and the linear slopes are denoted as $\mathrm{E}_{1-1}, \mathrm{E}_{1-2}, \mathrm{E}_{2-1}$, and $\mathrm{E}_{2-2}$ from lower $T_{\mathrm{a}}$ side on the figures. Note that under the measuring conditions for TSC the slope $\mathrm{E}_{2-1}$ for sample $\mathrm{C}_{10} \mathrm{Hs}_{15}$ and the slope $\mathrm{E}_{2-2}$ for sample $\mathrm{C}_{10} \mathrm{Na}_{11}$ seem to be not visible. In similar manner, for Group $B$ the 1082

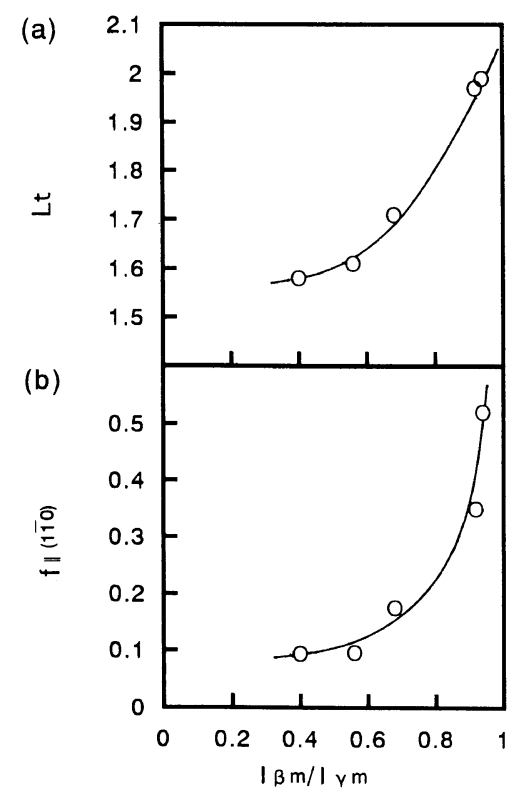

Figure 8. Dependence of swelling anisotropy parameter $L_{\mathrm{t}}$ (a) and plane orientation coefficient $f_{\|(1 \overline{1} 0)}$ (b) on $I_{\beta \mathrm{m}} / I_{\gamma \mathrm{m}}$ evaluated at the above $T_{\mathrm{t} 2}$.

slopes $\mathrm{E}_{1-1}, \mathrm{E}_{2-1}$, and $\mathrm{E}_{2-2}$ are observed and characteristically the slope $E_{1-2}$ seems to be absent. These calculated activation energy parameters denoted as $\Delta \mathrm{E}_{1-1}, \Delta \mathrm{E}_{1-2}, \Delta \mathrm{E}_{2-1}$, and $\Delta \mathrm{E}_{2-2}$ are listed also in Table II. $\Delta \mathrm{E}_{1-1}$ values $(18-75)$ are less than others, indicating that the vaporization of excess water in the membranes slowly moves molecular aggregate into some ordered structure. Subsequent sudden increase in $\Delta \mathrm{E}_{1-2}$ values ( $>140$ ) for Group A suggests that the integration of molecular aggregates into more ordered structure takes place, as has been pointed out by authors, ${ }^{1}$ when water content in the membrane diminished from that given at $T_{\mathrm{a}}=30$ and to that given at $T_{\mathrm{a}}=50^{\circ} \mathrm{C}$. The proceeding to subsequent non-consecutive $T_{\mathrm{a}}$ region might indicate that the sudden molecular integration is followed by some molecular relaxation. On the other hand, $\Delta \mathrm{E}_{1-2}$ is not detected for Group $B$, indicating that abrupt change in long-periodicity is hard to take place for Group B owing to their low $\chi_{\mathrm{c}}$ and $f_{\|(1 \overline{1} 0)}$, described before. ${ }^{1} \Delta \mathrm{E}_{2}$ on the whole is larger than $\Delta E_{1}(18-75)$, indicating that the structural change in higher $T_{\mathrm{a}}$ is somewhat more difficult than that occurred in lower $T_{\mathrm{a}}$ due to the low content 


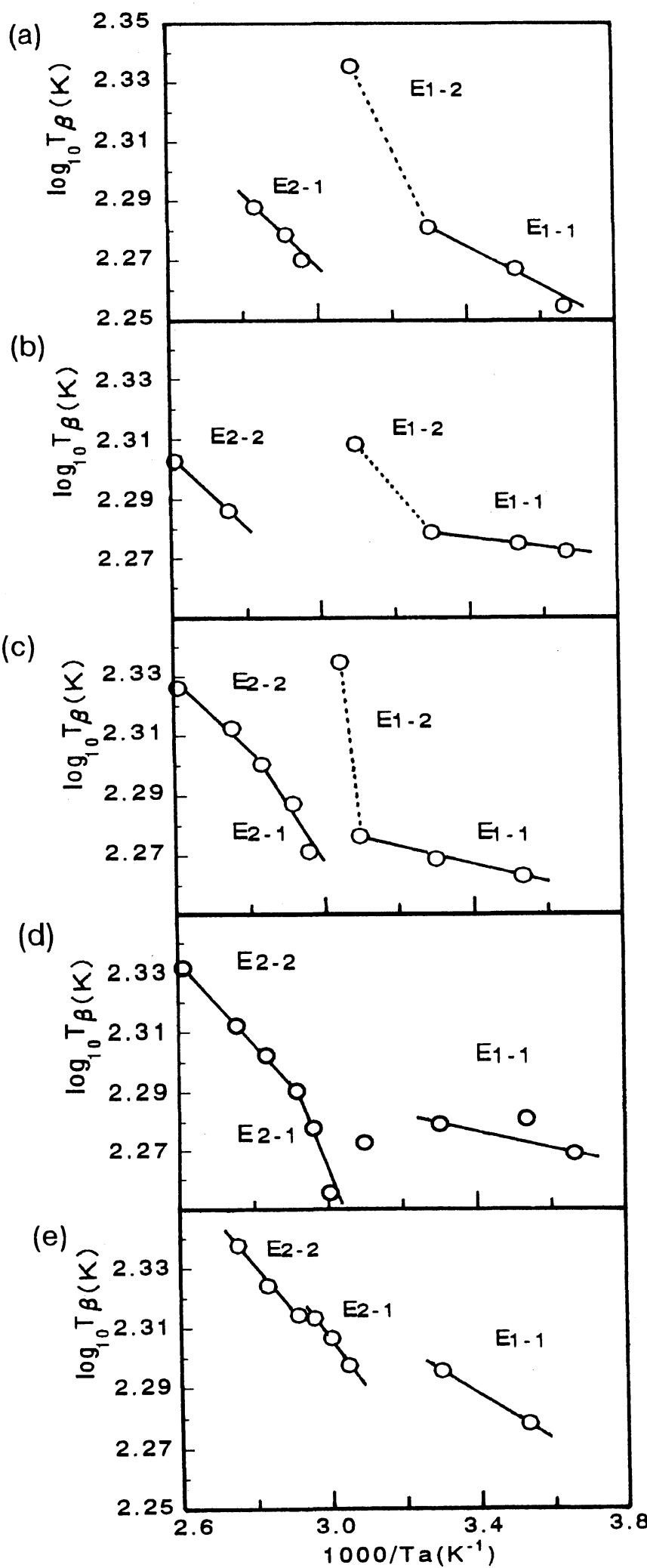

Figure 9. A tentative plot of $\ln T_{\beta}$ against $T_{\mathrm{a}}$. a, $\mathrm{C}_{10} \mathrm{Na}_{11} ; \mathrm{b}, \mathrm{C}_{10} \mathrm{Hs}_{15}$; $\mathrm{c}, \mathrm{C}_{07} \mathrm{Ca}_{10} ; \mathrm{d}, \mathrm{C}_{07} \mathrm{Ac}_{30} ; \mathrm{e}, \mathrm{D}_{03} \mathrm{~T}_{50}$.

of water in the system on its vaporization. However, despite the smaller water content in the membranes $\Delta \mathrm{E}_{2-1}(174-400)$ is larger than $\Delta \mathrm{E}_{2-2}(112-144)$, indicating that another molecular integration, which is hard to be considered due to structural formation based on simple vaporization of water, takes place around $T_{\mathrm{a}}=50-80^{\circ} \mathrm{C} . \Delta \mathrm{E}_{2-2}$ for Group $\mathrm{B}$ is somewhat larger than that for Group A. Because Group B showed low

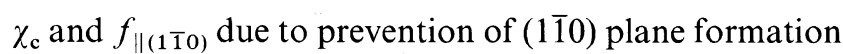
by organic solvent system. ${ }^{1}$ Therefore Group B indicated low swelling anisotropy originated from low $f_{\|(1 \overline{1} 0)}$. And the structure change against water for Group $B$ is considered to be more stable than that for Group A, as proved previously that $T_{\max \alpha \mathrm{H}_{2} \mathrm{O}}$ (corresponding to TSC $\beta$ ) is higher than that for Group A. ${ }^{1}$ In this connection, such sudden change might be related to sudden change in long periodicity of (110) plane, as reported previously. ${ }^{1}$

\section{CONCLUSION}

Thermally stimulated depolarized current (TSC) analysis was applied to elucidate the structural change of regenerated cellulose membranes caused by the vaporization of water. Five kinds of regenerated cellulose membranes having different swelling anisotropy parameter $L_{\mathrm{t}}$ and plane orientation factor $f_{\|(1 \overline{1} 0)}$ were utilized for this purpose. The membranes first dipped in water at $25^{\circ} \mathrm{C}$ for $5 \mathrm{~min}$ were subject to TSC measurement as a function of annealing temperature $T_{\mathrm{a}}$ from 10 to $130^{\circ} \mathrm{C}$, that is water content from high to low. Three broad peaks were detected and denoted as $\operatorname{TSC} \alpha, \operatorname{TSC} \beta$, and TSC $\gamma$ from the higher temperature side. TSC $\beta$ was found to decrease in its depolarized current $I_{\beta}$ with an increase in $T_{\mathrm{a}}$ while $I_{\gamma}$ of TSC $\gamma$ also decreases up to $T_{\mathrm{a}}=T_{\mathrm{t} 2}$ then increases. It was found that these relaxations were composed of at least three and two components, respectively, by thermal window analysis reducing to $\Delta S^{*}-\Delta H^{*}$ relation, and that one relaxation positioned at lowest temperature region of TSC $\gamma$ (two components) give completely reversed slope of $\Delta S^{*}-\Delta H^{*}$ relation depending on water content in the membrane and the other component is relatively insensitive to water. Three components of TSC $\beta$ and two components of TSC $\gamma$ attributed to mechanical relaxations $\alpha_{\mathrm{H}_{2} \mathrm{O}}$ and $\beta$ observed on $\tan \delta-T$ curves. The peak temperatures $\left(T_{\beta}\right.$ and $\left.T_{\gamma}\right)$ and their currents $\left(I_{\beta}\right.$ and $\left.I_{\gamma}\right)$ as a function of $T_{\mathrm{a}}$, and $\ln T_{\beta}-1 / T_{\mathrm{a}}$ plot revealed two sudden molecular integration region around $T_{\mathrm{a}}=30-50$ and $T_{\mathrm{a}}=50$ $80^{\circ} \mathrm{C}$, of which former relates to the sudden change in long periodicity of (110) plane. The ratio of $I_{\beta}$ and $I_{\gamma}$ at the above $T_{12}$ was proved to be closely related to $L_{\mathrm{t}}$ and $f_{\|(1 \overline{1} 0)}$.

\section{REFERENCES}

1. T. Hongo, C. Yamane, M. Saitoh, and K. Okajima, Polym. J., 28, 9, 769 (1996).

2. H. Eyring, J. Chem, Phys., 3, 107 (1935).

3. A. Sawatari, "Study in Electrical and Electronic Engineering," Vol. 2, Elsevier, Amsterdam, New York, N.Y., 1979, p 347.

4. T. Koizumi and K. Okajima, unpublished results.

5. A. Anagnostopoulou-Konsta, L. Apekis, C. Christodoulides, D. Daoukaki, and P. Pissis, in "Biologically Inspired Physics," L. Peliti, Ed., Plenum Press, New York, N.Y., 1991, p 229.

6. S. Manabe, M. Iwata, and K. Kamide, Polym. J., 18, 1, 1 (1986).

7. C. Yamane, M. Mori, M. Saitoh, and K. Okajima, Polym. J. 28, 12, 1039 (1996).

8. S. Manabe and R. Fujioka, to be submitted to Polym. J.

9. C. Yamane, M. Saitoh, and K. Okajima, to be submitted to Polym. J.

10. The Society of Thermal Analysis Japan, "Netubunseki no Kiso to Ouyou," Kagakugijyutusha, Tokyo, 1985, p 130. 